\title{
Proteomic and metabolomic analysis on the toxicological effects of As (III) and As (V) in juvenile mussel Mytilus galloprovincialis
}

\author{
Deliang $\mathrm{Yu}^{\mathrm{a}}{ }^{\mathrm{b}}$, Chenglong Ji ${ }^{\mathrm{a}}$, Jianmin Zhao ${ }^{\mathrm{a}}$, Huifeng $\mathrm{Wu}^{\mathrm{a}}$, * \\ a Key Laboratory of Coastal Zone Environmental Processes, Yantai Institute of Coastal Zone Research (YIC), Chinese Academy of Sciences (CAS), Shandong \\ Provincial Key Laboratory of Coastal Zone Environmental Processes, YICCAS, Yantai 264003, PR China \\ ${ }^{\mathrm{b}}$ University of Chinese Academy of Sciences, Beijing 100049, PR China
}

\section{H I G H L I G H T S}

- As (III) and As (V) induced differential proteomic responses in mussels.

- As (III) and As (V) induced osmotic and immune stresses in mussels.

- As (V) disturbed energy metabolism at metabolite level in mussels.

\section{A R T I C L E I N F O}

\section{Article history:}

Received 21 December 2015

Received in revised form

25 January 2016

Accepted 27 January 2016

Available online $\mathrm{xxx}$

Handling Editor:David Volz

\section{Keywords:}

Mytilus galloprovincialis

Arsenic

Toxicological effects

Metabolomics

Proteomics

\section{G R A P H I C A L A B S T R A C T}

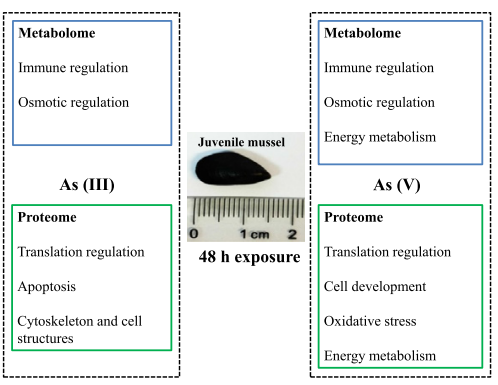

\begin{abstract}
A B S T R A C T
Inorganic arsenic (As) is a known pollutant including two chemical forms (arsenite (As III) and arsenate (As V)), in marine and coastal environment. Marine mussel Mytilus galloprovincialis is an important environmental monitoring species around the world. In this study, we focused on valence-specific responses of As in juvenile mussel M. galloprovincialis using a combined proteomic and metabolomic approach. Metabolic responses indicated that As (III) mainly caused disturbance in osmotic regulation in juvenile mussels. As (V) caused disturbances in both osmotic regulation and energy metabolism marked by different metabolic responses, including betaine, taurine, glucose and glycogen. Proteomic responses exhibited that As (III) had a significant negative effect on cytoskeleton and cell structure (actin and collagen alpha-6(VI) chain). As (V) affected some key enzymes involved in energy metabolism (cytosolic malate dehydrogenase, cMDH) and cell development (ornithine aminotransferase and astacin). Overall, all these results confirmed the valence-specific responses in juvenile mussels to As exposures. These findings demonstrate that a combined metabolomic and proteomic approach could provide an important insight into the toxicological effects of environmental pollutants in organisms.
\end{abstract}

(๑) 2016 Elsevier Ltd. All rights reserved.

\section{Introduction}

Arsenic (As) is involved in many chemicals and exists in a

\footnotetext{
* Corresponding author.

E-mail address: hfwu@yic.ac.cn (H. Wu).
}

number of inorganic and organic forms in marine environment (Hughes et al., 2011; Mandal and Suzuki, 2002; Tuzen, 2009). As an environmental pollutant, arsenic is toxic to marine organisms (Neff, 1997). Due to the fast development of industry and agriculture, As was released to estuarine and coastal environments with an average amount of more than 5000 tons/year from 2007 to 2010 in China from a variety of ways (e.g. the discharge of waste waters 
from mining and smelting, fertilizing and pesticides) (Mandal and Suzuki, 2002; Bissen and Frimmel, 2003; Tuzen, 2009; Wu et al., 2013; Gao et al., 2014).

As has a complex marine biogeochemistry that has important implications for its toxicity to human and marine organisms (Bissen and Frimmel, 2003). In the context of human health risk assessment, previous studies mainly focused on the exposure to As in drinking water and air (Worldwide, 2003; Kapaj et al., 2006). However, the toxicological effects of As was scarcely characterized in marine organisms (Hughes et al., 2011). The toxicity of As to organisms is dependent on its chemical forms and oxidation states. Due to their wide distribution and high bioavailability, inorganic arsenic (As (III) and As (V)) are the most toxic forms in marine ecosystems than organic forms of arsenic (Bissen and Frimmel, 2003; Wu et al., 2013; Gao et al., 2014). The dominant form of arsenic in oxygenated marine is As (V). However, the As (III) is more toxic than As (V) and accounts for more than $10 \%$ of total arsenic in seawater and As (III) is resorbed faster in biological systems than As (V) (Bissen and Frimmel, 2003). Usually, the concentration of As in waters changes frequently and seasonally from 0.5 to $3.4 \mu \mathrm{g} / \mathrm{L}$ in coastal and estuary areas along the Bohai Sea (Gao et al., 2014). In some heavily polluted sites along the Bohai Bay, however, the concentration of total arsenic in seawater has been up to $400 \mu \mathrm{g} / \mathrm{L}$ (Meng et al., 2004).

In marine ecotoxicology, mussels are widely used in environmental monitoring and assessment programs among marine organisms because of their sessile filter, feeding lifestyle and high accumulation for organic and inorganic pollutants in the marine environment (Goldberg et al., 1983; Jernelov, 1996). Recent studies have reported that As can be frequently found in most marine bivalves, especially mussels (Barmo et al., 2013; Gomes et al., 2013; Hanna et al., 2013; Marigómez et al., 2013; Sureda et al., 2013; Tsiaka et al., 2013; Voorhees et al., 2013). Generally, juvenile mussels ( $<20 \mathrm{~mm},<1$ year) are more sensitive than adults (Salazar and Salazar, 1987). However, the differential response mechanisms of juvenile mussels under As (III) and As (V) stresses were not fully characterized (Bayne, 1985; Salazar and Salazar, 1987). As a consequence, it is necessary to study the responsive mechanism of juvenile mussel to environmentally relevant concentration of As at early stages.

With the development of -omic techniques (including genomics, transcriptomics, proteomics and metabolomics), increasing biological and ecological problems such as ocean acidification, food chain competitions and environmental effects of pollutants have been explored by using -omic techniques (Li et al., 2006; Santos et al., 2010; Fu et al., 2013; Poulson-Ellestad et al., 2014; Wei et al., 2015a, 2015b. In this work, the toxicological effects of arsenite (As (III)) and arsenate (As (V)) were characterized by a combined metabolomic and proteomic approach in juvenile mussel Mytilus galloprovincialis after acute exposure for $48 \mathrm{~h}$ to elucidate the differential effects of As (III) and As (V) in juvenile mussels.

\section{Materials and methods}

\subsection{Animals and experimental design}

Juvenile mussels $M$. galloprovincialis (shell length: $0.5-1.5 \mathrm{~cm}$, $n=90$ ) were collected in July 2014 in a pristine site (Guangdang River Estuary, Yantai, China). The mussels were transported to the laboratory and then acclimatized in aerated natural seawater (salinity $31 \mathrm{psu}$ ) for 7 days. Then the mussels were randomly divided into three groups (control, $50 \mu \mathrm{g} / \mathrm{L}$ As (III) of $\mathrm{NaAsO}_{2}$ and $50 \mu \mathrm{g} / \mathrm{L}$ As ( $(\mathrm{V})$ of $\mathrm{Na}_{3} \mathrm{AsO}_{4}$ ) each containing 30 individuals. These mussels were cultured in the normal filtered seawater (FSW). During the acclimation and exposure periods, all the mussels were kept at $25^{\circ} \mathrm{C}$ under a photoperiod of $12 \mathrm{~h}$ light and $12 \mathrm{~h}$ dark, and fed with the Chlorella vulgaris at a ratio of $2 \%$ of tissue per dry weight daily. After exposure for 48 h, no morality of mussels was found in each group. Then all the mussels were immediately dissected for the whole soft tissues. The mussel tissues were snapfrozen in liquid nitrogen, and then stored at $-80^{\circ} \mathrm{C}$. For proteomics experiment, 3 biological replicates were used in each treatment. In our work, each treatment consisted of 6 mussels for proteomics, so 2 mussel samples were pooled into 1 for proteomic analysis.

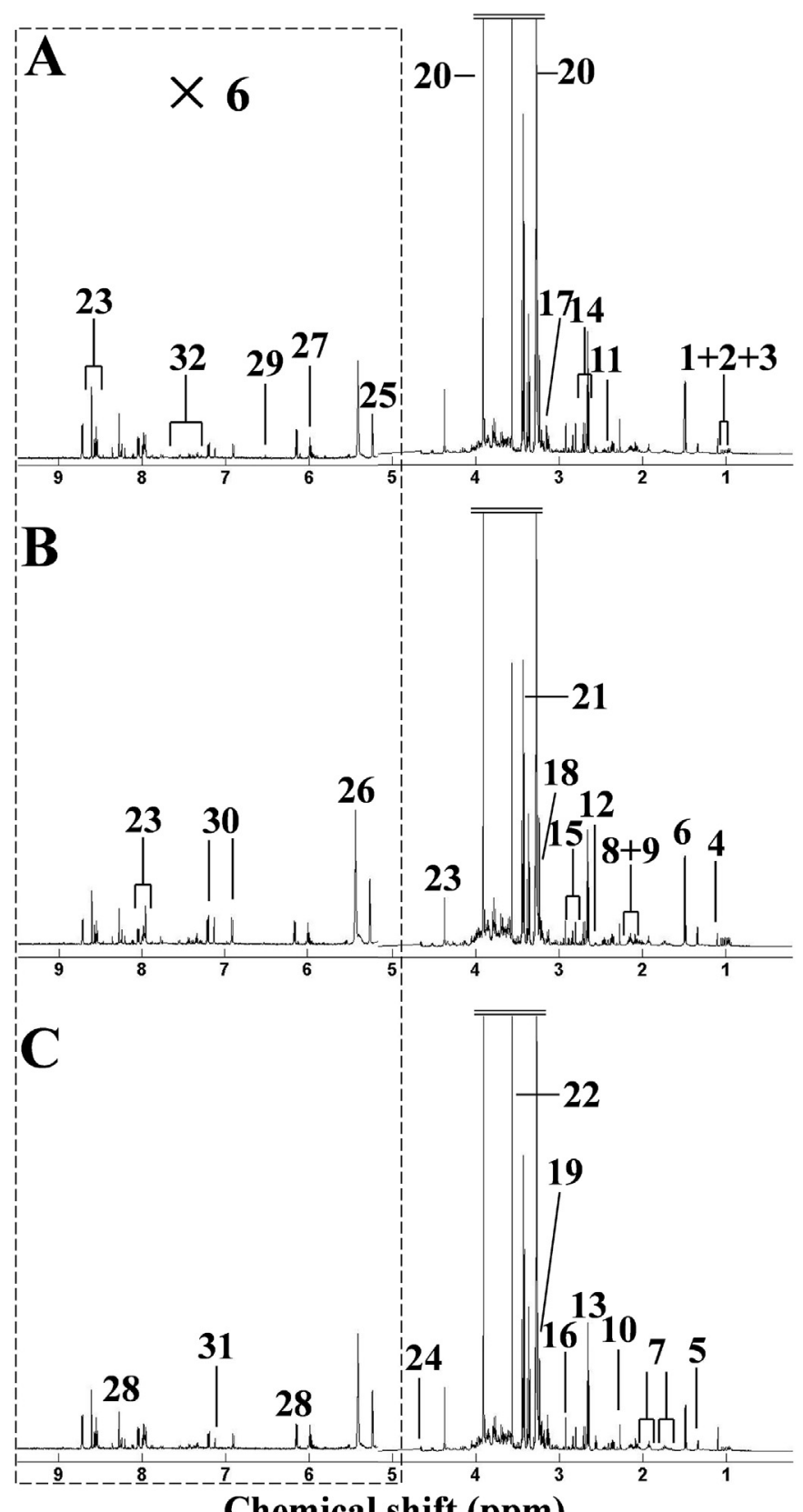

Chemical shift (ppm)

Fig. 1. Representative 1-dimensional ${ }^{1} \mathrm{HNMR}$ spectra of soft tissue extracts from control (A), As (III)-(B) and As (V)-treated (C) juvenile mussels M. galloprovincialis. Keys: (1) leucine, (2) isoleucine, (3) valine, (4) unknown 1 (1.10 ppm), (5) threonine, (6) alanine, (7) arginine, (8) glutamate, (9) glutamine, (10) acetoacetate, (11) succinate, (12) $\beta$-alanine, (13) hypotaurine, (14) aspartate, (15) asparaginine, (16) dimethylglycine, (17) malonate, (18) choline, (19) phosphocholine, (20) betaine, (21) taurine, (22) glycine, (23) homarine, (24) $\beta$-glucose, (25) $\alpha$-glucose, (26) glycogen, (27) unknown 3 (5.96 ppm), (28) ATP, (29) fumarate, (30) tyrosine, (31) histidine and (32) phenylalanine. 
2.2. Measurement of antioxidant enzyme activities and MDA content of juvenile mussels

In this work, the commercial enzyme kits (Jiancheng Ltd., Nanjing, China) were applied for the measurements of activities of antioxidant enzymes including superoxide dismutase (SOD, EC 1.15.1.1, kits number: A001-1), glutathione S-transferases (GST, EC 2.5.1.18, kits number: A004 GSH-ST) catalase (CAT, EC 1.11.1.6, kits number: A007-1) and the content of malondialdehyde (MDA, kits number: A003-1). The antioxidant enzyme activities and MDA content were assayed by using a multiskan spectrum microplate spectrophotometer (Infinite M200, TECAN). More details about the measurement and results of antioxidant enzyme activities and MDA content (Fig. S1) were described in the Supporting Information.

\subsection{Metabolomic analysis of juvenile mussels}

Polar metabolites in mussel tissues ( $n=8$ for each treatment) were extracted by the extraction protocol with some modifications. All the tissues (ca. $100 \mathrm{mg}$ wet weight) were homogenized and extracted in $4 \mathrm{~mL} / \mathrm{g}$ of methanol, $5.25 \mathrm{~mL} / \mathrm{g}$ of water and $2 \mathrm{~mL} / \mathrm{g}$ of chloroform (Lin et al., 2007; Wu et al., 2008). Metabolite extracts of mussel tissues samples were analyzed on a Bruker AV 500 NMR spectrometer. The analysis was performed at $500.18 \mathrm{MHz}$ (at $25^{\circ} \mathrm{C}$ ) as described previously (Liu et al., 2011).

All NMR spectra were processed using custom-written ProMetab software in Matlab (version 7.0; The MathWorks, Natick, MA, USA) (Liu et al., 2011), each spectrum was segmented into $0.005 \mathrm{ppm}$ bins between 0.2 and $10.0 \mathrm{ppm}$. All NMR spectra were generalized $\log$ (gLog) transformed with a transformation parameter $\lambda=2.0 \times 10^{-9}$ to stabilize the variance across the spectral bins
(Liu et al., 2011). The NMR spectral matrix data were meancentered before multivariate data analysis. More details about metabolomic analysis were described in the Supporting Information.

\subsection{Proteomic analysis of juvenile mussels}

Total protein extraction was performed based on previous studies (Kirkland et al., 2006; Lee and Lo, 2008) with some modifications. Briefly, the mussel soft tissue was homogenized quickly on ice with $1 \mathrm{~mL}$ of TRIzol reagent at $4{ }^{\circ} \mathrm{C}$ to extract proteins. The protein pellets were solubilized in the lysis buffer ( $7 \mathrm{M}$ urea; $2 \mathrm{M}$ thiourea; $4 \% \mathrm{~m} / \mathrm{V}$ CHAPS; $65 \mathrm{mM}$ DTT and 0.2\%W/V Bio-lyte buffer) and then incubated for $3 \mathrm{~h}$ at room temperature (Tullius et al., 2002). The homogenate was centrifuged at $15,000 \mathrm{~g}$ for $10 \mathrm{~min}$ and the supernatant was applied to electrophoresis. The total concentrations of proteins were determined by Protein Assay Kit of TianGen.

Two-dimensional gel electrophoresis (2-DE) technique was applied to proteomic analysis. For the first dimension (IEF), $130 \mu \mathrm{g}$ of protein was loaded onto IPG strips with a linear $\mathrm{pH}$ gradient from 4 to 7 (Immobiline Drystrip TM $24 \mathrm{~cm}$, GE Healthcare, USA) The isoelectric focusing gel solution (7 M urea, $2 \mathrm{M}$ thiourea, $4 \% \mathrm{~m} / \mathrm{v}$ CHAPS, $65 \mathrm{mM}$ DTT, $0.001 \% \mathrm{~m} / \mathrm{v}$ bromophenol blue and $0.2 \% \mathrm{~W} / \mathrm{V}$ Bio-lyte buffer). The second dimension was conducted on $12.5 \%$ SDS-PAGE gels using the Ettan DALTsix system. After electrophoresis, the gels were silver stained by following the method of Mortz and Gharahdaghi (Gharahdaghi et al., 1999; Mortz et al., 2001). Images were captured by ImageScanner III and spots were quantitatively analyzed using ImageMaster 2D Platinum 7.0. For all the matched spots, only protein spots with significant changes of at least 1.2-fold, and deemed significant by Student's t-test at a level of
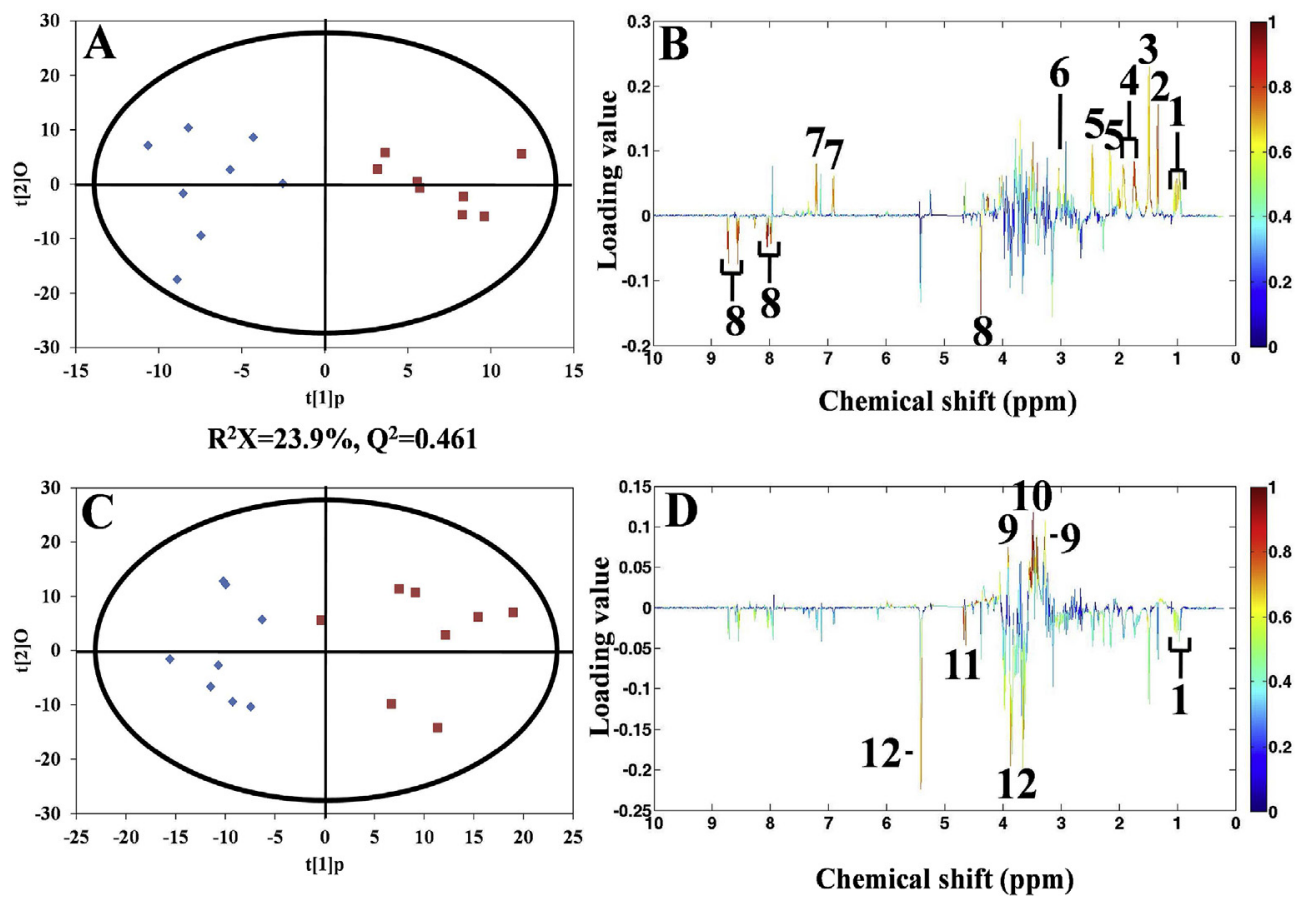

$R^{2} X=58.6 \%, Q^{2}=0.609$



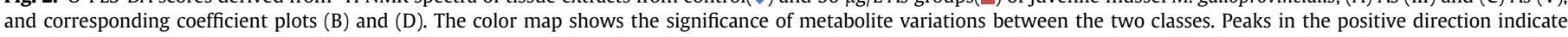




glycogen (For interpretation of the references to colour in this figure legend, the reader is referred to the web version of this article). 
95\% were accepted as differentially expressed proteins. More details about proteomic analysis were described in the Supporting Information.

\subsection{As concentrations in soft tissues of juvenile mussels}

Details are described in the Supporting Information.

\section{Results and discussion}

\subsection{Effects of As on the metabolome of juvenile mussels}

Fig. 1 presents the representative ${ }^{1} \mathrm{H}$ NMR spectra of tissue extracts from juvenile mussels in control and As-treated groups with the labeled metabolites. O-PLS-DA demonstrated significant $(p<0.05)$ metabolic responses in As (III)- and As (V)-exposed groups of mussels with reliable $Q^{2}$ values of 0.461 and 0.609 , respectively (Fig. 2). Multiple classes of metabolites were significantly $(p<0.05)$ altered including amino acids (branched chain amino acids (BCAAs), threonine, alanine, arginine, glutamine, lysine and tyrosine), organic osmolytes (homarine, betaine and taurine) and energy storage compounds (glucose and glycogen) (Viant et al., 2003; Moghaieb et al., 2004; Wu and Wang, 2010). As shown in Fig. 2A and B, the levels of amino acids (BCAAs, threonine, alanine, arginine, glutamine, lysine and tyrosine) from the tissues of mussels exposed by As (III) were significantly increased. With regard to the As (V)-exposed mussel samples, the O-PLS-DA also showed clear separation between the control and As (V)-exposed group (Fig. 2C). Some metabolites, including betaine, taurine, glucose and glycogen were uniquely altered (Fig. 2D).

Amino acids usually play key roles in multiple pathways in marine mollusks. Free amino acids can be employed as organic osmolytes to regulate the intracellular osmolarity with the environment (Wu and Wang, 2010). The altered amino acid profiles might indicate the disturbances in osmotic regulation induced by both As (III) and As (V). Meanwhile, some organic osmolytes (homarine, betaine and taurine) were significantly altered in juvenile mussel tissues under As (III) and As (V) exposures, which also meant osmotic stress induced by As (III) and As (V). The decreased energy storage compounds (glucose and glycogen) in mussel tissues indicated the disturbance in energy metabolism caused by As (V) exposure (Wei et al., 2015a). BCAAs are involved in the immune system to function by incorporating BCAAs into proteins (Calder, 2006). They can provide energy and be used as the precursors for the biosynthesis of protective molecules (Calder, 2006). Therefore, the altered BCAAs might suggest the immune stress in juvenile mussel induced by As (III) and As (V) exposures. Previous studies confirmed that As exposures could induce immune stress in mollusks indicated by the altered immune effector cells haemocytes and some immune-related enzymes (acid phosphatase and phenoloxidase) (Jing et al., 2007; Chakraborty and Ray, 2009; Ray et al., 2015). The changes of all these metabolites suggested that the As (III) and As (V) exposures might induce disturbance in osmotic regulation and immune system in juvenile mussels via differential metabolic pathways. In addition, As (V) disturbed energy metabolism in juvenile mussels.

\subsection{Effects of As on the proteome of juvenile mussels}

The representative 2-DE gels of control and As-exposed mussel groups are shown in Fig. 3. The quantitative comparisons of protein spots ( 4000) were conducted by ImageMaster 2D Platinum 7.0 software. To detect the protein biomarkers induced by As (III) and As $(\mathrm{V})$ treatments in juvenile mussels, the 2-DE gels obtained from As (III)- and As (V)-exposed mussel samples were compared to
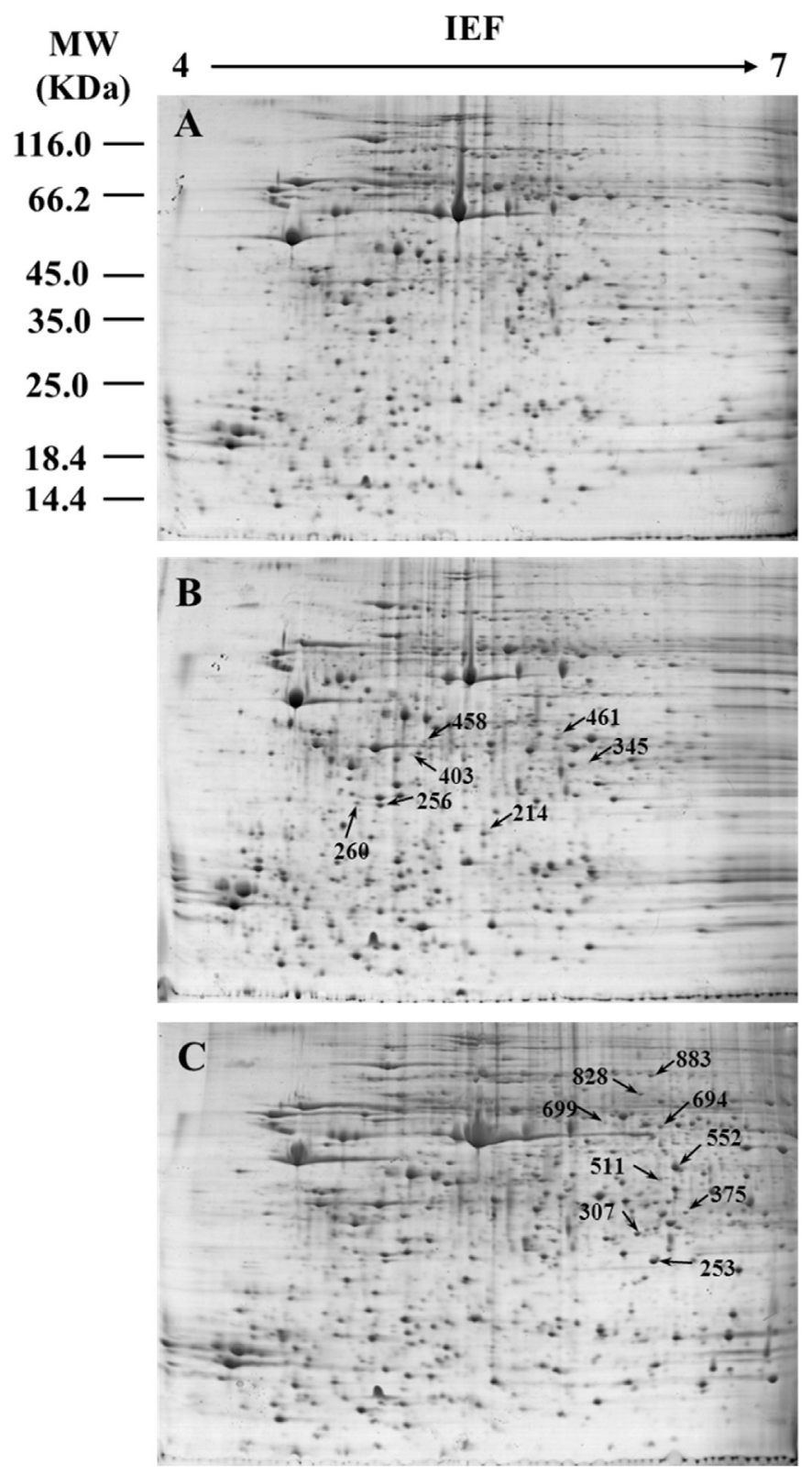

Fig. 3. Representative 2-D gels of proteins extracted from soft tissues of juvenile mussels Mytilus galloprovincialis. First dimension was performed using $130 \mu \mathrm{g}$ of total soluble proteins on linear gradient IPG strips with $\mathrm{pH} 4-7$. In the second dimension, 12.5\% SDS-PAGE gels were used and proteins were visualized using silver staining. (A) control group, (B) As (III)-exposed group under $50 \mu \mathrm{g} / \mathrm{L}$ and (C) As (V)-exposed group under $50 \mu \mathrm{g} / \mathrm{L}$. Arrows show protein spots that changed significantly from inorganic As-exposed group compared to the control group.

those from control group, respectively. A total of sixteen protein spots resolved in 2-DE gels were significantly altered in abundance $(p<0.05)$ from As (III)- and As (V)-exposed mussel samples, the details of all identified proteins including their spot IDs, protein names, gi numbers and other MS data were summarized in Table 1 and 2 , respectively.

\subsubsection{Effects of As (III) on the proteome of juvenile mussels}

Table 1 lists seven proteins that were significantly altered in juvenile mussel under As (III)-exposed mussel group. Proteins of 14-3-3 family are involved in various important cellular processes. They can also be bound to a variety of signal proteins such as the 
Table 1

List of protein spots that differentially expressed in juvenile Mytilus galloprovincialis exposed to As (III) under $50 \mu \mathrm{g} / \mathrm{L}$.

\begin{tabular}{|c|c|c|c|c|c|c|c|c|c|}
\hline Spot ID ${ }^{\mathrm{b}}$ & Category and name & Species & gi number ${ }^{c}$ & $\mathrm{MW} / \mathrm{kDa}^{\mathrm{d}}$ & PI & Protein score $^{\mathrm{e}}$ & $\mathrm{SC}^{\mathrm{f}}$ & $\mathrm{PN}^{g}$ & Fold change $^{\mathrm{h}}$ \\
\hline 214 & zinc finger lsd 1 subclass family protein & Tetrahymena thermophila SB210 & 586733233 & 24.034 & 5.32 & 335 & $46 \%$ & 3 & -1.35 \\
\hline 256 & Actin, muscle & Harpegnathos saltator & 307197033 & 29.664 & 5.42 & 65 & $15 \%$ & 3 & 1.42 \\
\hline 260 & hypothetical protein LOTGIDRAFT_154656 & Lottia gigantea & 676480571 & 26.64 & 8.14 & 36 & $13 \%$ & 2 & 1.33 \\
\hline 345 & Linear gramicidin synthetase subunit D & Crassostrea gigas & 405967002 & 23.55 & 4.78 & 315 & $33 \%$ & 3 & 1.3 \\
\hline 403 & $14-3-3$ protein zeta & Crassostrea gigas & 405950429 & 33.319 & 5.22 & 40 & $5 \%$ & 2 & -1.36 \\
\hline 458 & Collagen alpha- $6(\mathrm{VI})$ chain & Crassostrea gigas & 405958346 & 24.82 & 5.01 & 95 & $21 \%$ & 3 & 1.33 \\
\hline 461 & Phosphoenolpyruvate phosphomutase & Mytilus edulis & 41713045 & 33.063 & 5.51 & 312 & $35 \%$ & 6 & -1.39 \\
\hline
\end{tabular}

${ }^{a}$ Identification of differentially expressed proteins in juvenile M. galloprovincialis soft tissue between control and As (III)-exposed groups.

b Assigned spot ID as indicated in Fig. 3.

c Database accession numbers after searching against the NCBInr database.

d Experimental mass.

e Mascot score reported.

f Number of peptide sequences.

$\mathrm{g}$ Sequence coverage.

h Fold changes with significances $(>1.2$ folds and $p<0.05)$ were calculated using ImageMaster 2D Platinum 7.0.

Table 2

List of protein spots that differentially expressed in juvenile Mytilus galloprovincialis exposed to As (V) under $50 \mu \mathrm{g} / \mathrm{L}$.

\begin{tabular}{|c|c|c|c|c|c|c|c|c|c|}
\hline Spot $\mathrm{ID}^{\mathrm{b}}$ & Category and name & Species & gi number ${ }^{\mathrm{C}}$ & $\mathrm{MW} / \mathrm{kDa}^{\mathrm{d}}$ & PI & Protein score $\mathrm{e}^{\mathrm{e}}$ & $S C^{f}$ & $\mathrm{PN}^{\mathrm{g}}$ & Fold change ${ }^{h}$ \\
\hline 253 & mitochondrial manganese superoxide dismutase & Mytilus galloprovincialis & 402122769 & 25.227 & 8.4 & 441 & $30 \%$ & 3 & 1.31 \\
\hline 307 & hypothetical protein NEMVEDRAFT_v1g224392 & Nematostella vectensis & 156331945 & 21.167 & 6.28 & 49 & $7 \%$ & 1 & 1.37 \\
\hline 375 & Proteasome subunit alpha type- 6 & Crassostrea gigas & 405975869 & 26.24 & 8.73 & 166 & $38 \%$ & 5 & 1.55 \\
\hline 511 & eukaryotic translation initiation factor 3 subunit I-like & Astyanax mexicanus & 597771365 & 18.643 & 6.48 & 188 & $36 \%$ & 4 & 3.29 \\
\hline 552 & cytosolic malate dehydrogenase & Mytilus galloprovincialis & 73656337 & 19.359 & 8.89 & 456 & $46 \%$ & 3 & 1.61 \\
\hline 694 & Ornithine aminotransferase, mitochondrial & Crassostrea gigas & 405959157 & 47.933 & 7.95 & 141 & $7 \%$ & 2 & 1.3 \\
\hline 699 & Astacin & Crassostrea gigas & 405978762 & 14.549 & 7.66 & 118 & $27 \%$ & 2 & 1.71 \\
\hline 828 & Meiosis-specific nuclear structural protein 1 & Crassostrea gigas & 405955473 & 27.524 & 5.6 & 65 & $19 \%$ & 4 & 1.61 \\
\hline 883 & $60 \mathrm{kDa}$ neurofilament protein & Crassostrea gigas & 405963175 & 20.953 & 8.07 & 157 & $33 \%$ & 3 & 1.43 \\
\hline
\end{tabular}

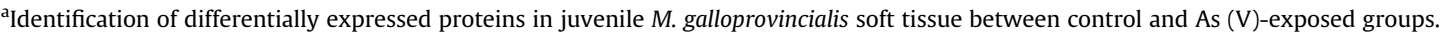

b Assigned spot ID as indicated in Fig. 3 .

c Database accession numbers after searching against the NCBInr database.

d Experimental mass.

e Mascot score reported.

f Number of peptide sequences.

g Sequence coverage.

h Fold changes with significances $(>1.2$ folds and $p<0.05)$ were calculated using ImageMaster 2D Platinum 7.0.

pro-apoptotic protein phosphorylated Bcl-2-associated death promoter protein (Bad protein) to prevent apoptosis (Wang et al., 2011). After exposed to $\mathrm{Hg}^{2+}$, medaka Oryzias melastigma was found to down-regulate the 14-3-3 protein in liver tissue (Wang et al., 2011). The similar down-regulation of 14-3-3 protein was also found in the gill tissue of adult M. galloprovincialis under BDE47 treatment (Ji et al., 2013). In this study, 14-3-3 protein was similarly down-regulated, which suggested the apoptosis induced by As (III) in juvenile mussels.

Actin plays critical roles in shaping and maintaining cell morphology, as well as in supporting various cellular functions, including cell motility, cell division, and intra-cellular transport (Allansson et al., 2001). Physiological stress could lead to increasing number of actin-containing stress fibers and change the characteristic of the growth-arrested state of cells (Thomas et al., 1981). Collagen is the major component of byssus and adhesive plaques. This protein is the main structural element of various connective tissues and can also form the extracellular matrix to support cells (Waite, 1983). The significant up-regulation of these proteins indicated that As (III) exposure perhaps influenced the stability of cytoskeleton and cell structures in juvenile mussels.

The family of zinc-finger proteins is one of the well-known transcription factor groups that can be used to bind specifically to short DNA-sequences and control many gene expressions. The descriptions of zinc-finger proteins have been reported as important regulators in response to environmental stressors (Hartwig, 2001; Gomes et al., 2014). A number of metals (e.g. Cu, Co, Cd and Fe) can replace zinc from $\mathrm{Zn}$-binding domains, which leads to the reduction of DNA-binding activity. Gomes et al. (2014) found that zinc-finger proteins were significantly down-regulated in gill tissue of adult mussel $M$. galloprovincialis exposed to $\mathrm{CuO}$ nanoparticles. In our work, up-regulation of zinc-finger protein was found in juvenile mussels, which suggested that As (III) induced different mechanism of disturbance in transcription regulation.

\subsubsection{Effects of As $(V)$ on the proteome of juvenile mussels}

Table 2 lists nine detected proteins that were significantly altered in abundance $(p<0.05)$ in As $(\mathrm{V})$-exposed group. However, these identified proteomic responses in As (V)-exposed mussel samples were completely different from those of As (III)-exposed group. Cytosolic malate dehydrogenase (cMDH) plays an important role in energy metabolism (Dahlhoff and Somero, 1993; Fields et al., 2006). The up-regulated $\mathrm{cMDH}$ in As (V)-exposed samples indicated that the energy metabolism was disturbed by As $(\mathrm{V})$ in juvenile mussel. However, a down-regulation of cMDH was observed in adult $M$. galloprovincialis under acute heat stress and the malate-aspartate shuttle was reduced in mussels (Salway, 2013). This indicated the different mechanisms of disturbance in energy metabolism conducted by As (V) exposure.

Ornithine aminotransferase (OAT) is a key enzyme in the ultimate formation process of proline from ornithine (Gillespie, 1964). OAT can balance the inter-conversion of a variety of amino acids for providing metabolic intermediates to cells for growth and protection (Sacheti et al., 2014). Astacin plays a key role in extracellular 


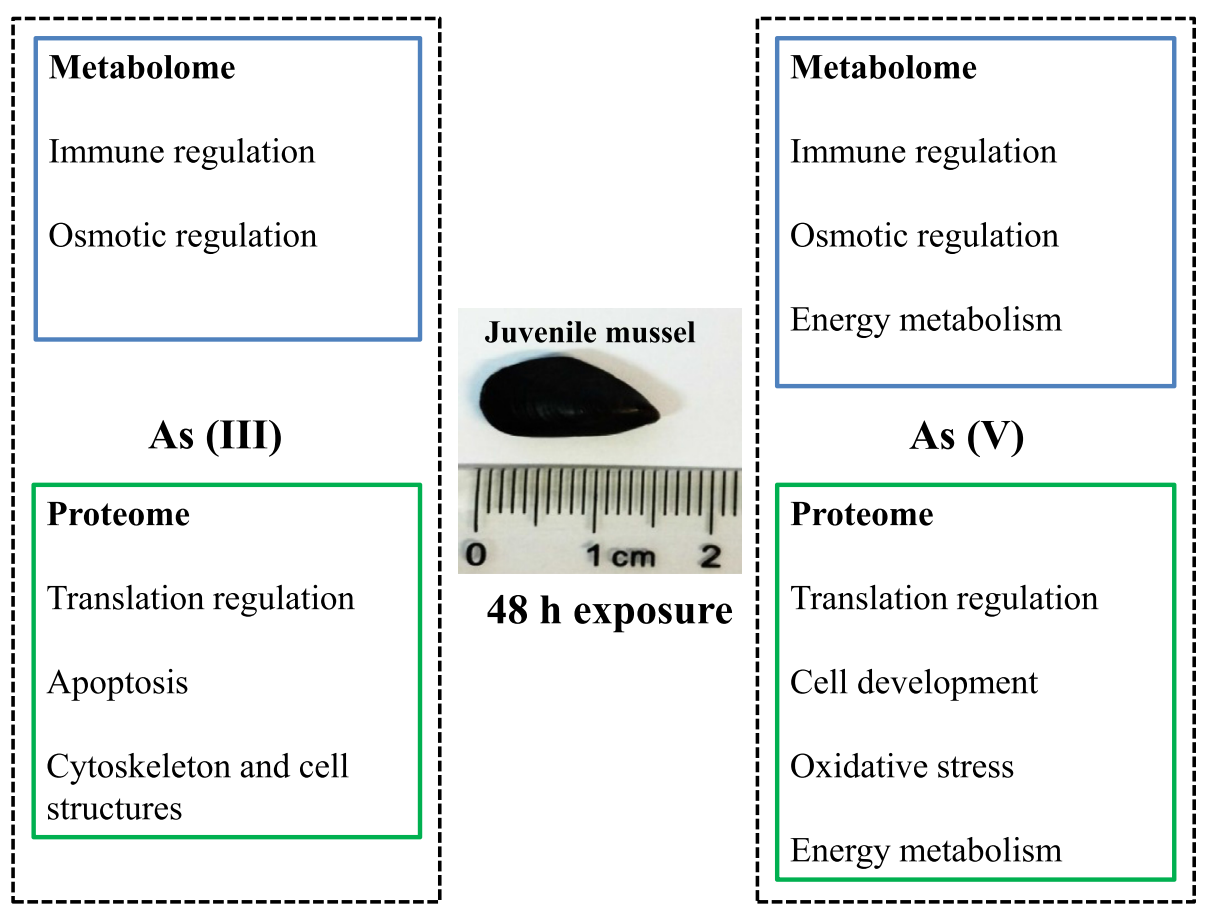

Fig. 4. The profiles of effects induced by $\mathrm{As}(\mathrm{III})$ and $\mathrm{As}(\mathrm{V})$ in juvenile mussels Mytilus galloprovincialis indicated by metabolomic and proteomic responses.

proteolysis during multiple biological processes including tissue development, morphogenesis, digestion and cell migration (Geier and Zwilling, 1998). The up-regulation of these two proteins suggested that As (V) exposure affected cell development in juvenile mussels.

Proteasomes is a key protein in the process of apoptosis (Möhrlen et al., 2006; Huber et al., 2012). In our study, the upregulation of proteasome subunit alpha type- 6 suggested that apoptosis was induced by As (V). The similar alteration of proteasomes was also observed in the gill tissue of male adult M. galloprovincialis exposed to BDE-47 (Ji et al., 2013). However, an opposite alteration of proteasomes was observed in M. galloprovincialis under $24{ }^{\circ} \mathrm{C}$ stress (Tomanek and Zuzow, 2010). It meant that a different apoptosis process was induced by heat stress compared with environmental contaminants, As (V) and BDE-47. As for the eukaryotic translation initiation factors (eIFs), the eIF family is responsible for the initiation of translation in eukaryotic cells by a sequence of well-defined partial reactions (Chaudhuri et al., 1997). The up-regulation of eukaryotic translation initiation factor 3 subunit I-like might indicate that the transcription regulation was disturbed by $A s(V)$. The oxidation-reduction (redox) enzyme, manganese superoxide dismutase (Mn-SOD) primarily functions as regulating cellular redox homeostasis and adjusting proliferative and quiescent growth states (Sarsour et al., 2014). The up-regulated Mn-SOD suggested that As (V) induced oxidative stress in juvenile mussels. However, the SOD activity was not significantly altered in As (V)-exposed group. Generally, SOD consists of two types ( $\mathrm{Cu}-\mathrm{Zn}-\mathrm{SOD}$ and $\mathrm{Mn}-\mathrm{SOD}$ ) in mussels, which might account for the un-regulated activity of SOD in the juvenile mussel under As (V) exposure (Muñoz et al., 2005). As a matter of fact, the activities of other antioxidant enzymes (catalase and glutathione S-transferases) and malondialdehyde (MDA) were measured in the mussel samples. However, there were no significant differences between control and As treatments (Table S1). Usually, there are several types for these antioxidant enzymes. Therefore, the different alterations of these different types might eliminate the significances of the total activities of these antioxidant enzymes. In addition, an environmentally relevant concentration $(50 \mu \mathrm{g} / \mathrm{L})$ of As was used for exposures, which could not lead to significant alterations of these antioxidant enzymes or MDA in As-exposed mussels.

\section{Conclusions}

In this work, we combined metabolomics and proteomics to characterize the responses to different valence state of As exposure in soft tissues of juvenile mussel $M$. galloprovincialis. Both metabolomic and proteomic analysis indicated that the responses of juvenile mussels to As (III) and As (V) were valence state-dependent. At metabolite level, both As (III) and As (V) caused disturbances in osmotic regulation and immune system in juvenile mussels via different metabolic pathways. However, As (V) disturbed energy metabolism as well. Proteomic responses suggested that As (III) and As (V) induced disturbance of transcription regulation and apoptosis by different protein responses, respectively. As (III) also had a significant negative effect on cytoskeleton and cell structure, while As (V) affected some key enzymes involved in energy metabolism and redox homeostasis. Overall, as shown in Fig. 4, all these results confirmed the valence-specific responses to As exposures in juvenile mussels. These findings demonstrate that a combined metabolomic and proteomic approach could provide an important insight into the toxicological effects of environmental pollutants in organisms.

\section{Acknowledgments}

This work was supported by National Key Basic Research Program of China (2015CB453303), Natural Science Foundation of Shandong Province (No. JQ201310) and National Natural Science Foundation of China (41206105). We thank Prof. Mark Viant (School of Bioscience, The University of Birmingham) for the use of ProMetab software. 
Appendix A. Supplementary data

Supplementary data related to this article can be found at http:// dx.doi.org/10.1016/j.chemosphere.2016.01.113.

\section{Conflicts of interest}

\section{The authors have declared on conflict of interest.}

\section{References}

Allansson, L., Khatibi, S., Olsson, T., Hansson, E., 2001. Acute ethanol exposure induces $\left[\mathrm{Ca}^{2+}\right]_{i}$ transients, cell swelling and transformation of actin cytoskeleton in astroglial primary cultures. J. Neurochem. 76, 472-479.

Barmo, C., Ciacci, C., Canonico, B., Fabbri, R., Cortese, K., Balbi, T., Marcomini, A. Pojana, G., Gallo, G., Canesi, L., 2013. In vivo effects of $\mathrm{n}-\mathrm{TiO}_{2}$ on digestive gland and immune function of the marine bivalve Mytilus galloprovincialis. Aquat. Toxicol. 132, 9-18.

Bayne, B.L., 1985. Effects of Stress and Pollution on Marine Animals. Praeger.

Bissen, M., Frimmel, F.H., 2003. Arsenic-a review. Part 1: occurrence, toxicity, speciation, mobility. Acta Hydrochim. Hydrobiol. 31, 9-18.

Calder, P.C., 2006. Branched-chain amino acids and immunity. J. Nutr. 136, 288s-293s.

Chakraborty, S., Ray, S., 2009. Nuclear morphology and lysosomal stability of molluskan hemocytes as possible biomarkers of arsenic toxicity. Clean-Soil Air Water 37, 769-775.

Chaudhuri, J., Si, K., Maitra, U., 1997. Function of eukaryotic translation initiation factor 1A (eIF1A) (formerly called eIF-4C) in initiation of protein synthesis. J. Biol. Chem. 272, 7883-7891.

Dahlhoff, E., Somero, G.N., 1993. Kinetic and structural adaptations of cytoplasmic malate-dehydrogenases of eastern Pacific abalone (Genus Haliotis) from different thermal habitats - biochemical correlates of biogeographical patterning. J. Exp. Biol. 185, 137-150.

Fields, P.A., Rudomin, E.L., Somero, G.N., 2006. Temperature sensitivities of cytosolic malate dehydrogenases from native and invasive species of marine mussels (genus Mytilus): sequence-function linkages and correlations with biogeographic distribution. J. Exp. Biol. 209, 656-667.

Fu, Z.R., Zhang, L., Liu, X.B., Zhang, Y.Z., Zhang, Q.L., Li, X.M., Zheng, W., Sun, L.L., Tian, J.K., 2013. Comparative proteomic analysis of the sun- and freeze-dried earthworm Eisenia fetida with differentially thrombolytic activities. J. Proteom. 83, 1-14.

Gao, X.L., Zhou, F.X., Chen, C.T.A., 2014. Pollution status of the Bohai Sea: an overview of the environmental quality assessment related trace metals. Environ. Int. $62,12-30$.

Geier, G., Zwilling, R., 1998. Cloning and characterization of a cDNA coding for Astacus embryonic astacin, a member of the astacin family of metalloproteases from the crayfish Astacus astacus. Eur. J. Biochem. 253, 796-803.

Gharahdaghi, F., Weinberg, C.R., Meagher, D.A., Imai, B.S., Mische, S.M., 1999. Mass spectrometric identification of proteins from silver-stained polyacrylamide gel: a method for the removal of silver ions to enhance sensitivity. Electrophoresis 20, 601-605.

Gillespie, F.D., 1964. Gyrate atrophy of choroid and retina. Am. J. Ophthalmol. 57, 317-320.

Goldberg, E.D., Koide, M., Hodge, V., Flegal, A.R., Martin, J., 1983. U.S. Mussel Watch: 1977-1978 results on trace metals and radionuclides. Estuar. Coast. Shelf Sci. 16, 69-93.

Gomes, T., Araújo, O., Pereira, R., Almeida, A.C., Cravo, A., Bebianno, M.J., 2013. Genotoxicity of copper oxide and silver nanoparticles in the mussel Mytilus galloprovincialis. Mar. Environ. Res. 84, 51-59.

Gomes, T., Chora, S., Pereira, C.G., Cardoso, C., Bebianno, M.J., 2014. Proteomic response of mussels Mytilus galloprovincialis exposed to $\mathrm{CuO}$ NPs and $\mathrm{Cu}^{2+}$ : an exploratory biomarker discovery. Aquat. Toxicol. 155, 327-336.

Hanna, S.K., Miller, R.J., Muller, E.B., Nisbet, R.M., Lenihan, H.S., 2013. Impact of engineered zinc oxide nanoparticles on the individual performance of Mytilus galloprovincialis. PLoS One 8.

Hartwig, A., 2001. Zinc finger proteins as potential targets for toxic metal ions: differential effects on structure and function. Antioxid. Redox Signal. 3, 625-634.

Huber, E.M., Basler, M., Schwab, R., Heinemeyer, W., Kirk, C.J., Groettrup, M., Groll, M., 2012. Immuno- and constitutive proteasome crystal structures reveal differences in substrate and inhibitor specificity. Cell 148, 727-738.

Hughes, M.F., Beck, B.D., Chen, Y., Lewis, A.S., Thomas, D.J., 2011. Arsenic exposure and toxicology: a historical perspective. Toxicol. Sci. 123, 305-332.

Jernelov, A., 1996. The international mussel watch: a global assessment of environmental levels of chemical contaminants. Sci. Total Environ. 188, S37-S44.

Ji, C.L., Wu, H.F., Wei, L., Zhao, J.M., Yu, J.B., 2013. Proteomic and metabolomic analysis reveal gender-specific responses of mussel Mytilus galloprovincialis to 2,2',4,4'-tetrabromodiphenyl ether (BDE 47). Aquat. Toxicol. 140, 449-457.

Jing, G., Li, Y., Xie, L., Zhang, R.Q., 2007. Different effects of $\mathrm{Pb}^{2+}$ and $\mathrm{Cu}^{2+}$ on immune and antioxidant enzyme activities in the mantle of Pinctada fucata. Environ. Toxicol. Pharmacol. 24, 122-128.
Kapaj, S., Peterson, H., Liber, K., Bhattacharya, P., 2006. Human health effects from chronic arsenic poisoning-A review. J. Environ. Sci. Heal. A 41, 2399-2428.

Kirkland, P.A., Busby, J., Stevens, S., Maupin-Furlow, J.A., 2006. Trizol-based method for sample preparation and isoelectric focusing of halophilic proteins. Anal. Biochem. 351, 254-259.

Lee, F.W.F., Lo, S.C.L., 2008. The use of Trizol reagent (phenol/guanidine isothiocyanate) for producing high quality two-dimensional gel electrophoretograms (2DE) of dinoflagellates. J. Microbiol. Methods 73, 26-32.

Li, Z.F., Wu, H.F., Zhang, X.Y., Li, X.J., Liao, P.Q., Li, W.S., Pei, F.K., 2006. Investigation on the acute biochemical effects of light rare earths (lanthanum and cerium) by NMR-based metabonomic approaches. Chem. J. Chin. Univ. 27, 438-442.

Lin, C.Y., Wu, H.F., Tjeerdema, R.S., Viant, M.R., 2007. Evaluation of metabolite extraction strategies from tissue samples using NMR metabolomics. Metabolomics 3, 55-67.

Liu, X.L., Zhang, L.B., You, L.P., Yu, J.B., Zhao, J.M., Li, L.Z., Wang, Q., Li, F., Li, C.H., Liu, D.Y., Wu, H.F., 2011. Differential toxicological effects induced by mercury in gills from three pedigrees of Manila clam Ruditapes philippinarum by NMRbased metabolomics. Ecotoxicology 20, 177-186.

Mandal, B.K., Suzuki, K.T., 2002. Arsenic round the world: a review. Talanta 58, 201-235.

Marigómez, I., Garmendia, L., Soto, M., Orbea, A., Izagirre, U., Cajaraville, M.P., 2013 Marine ecosystem health status assessment through integrative biomarker indices: a comparative study after the Prestige oil spill "Mussel Watch". Ecotoxicology 22, 486-505.

Meng, W., Liu, Z., Fan, W., 2004. Study on pollutant characters of main estuary of the Bohai Bay (in Chinese). Res. Environ. Sci. 17, 66-69.

Moghaieb, R.E.A., Saneoka, H., Fujita, K., 2004. Effect of salinity on osmotic adjustment, glycinebetaine accumulation and the betaine aldehyde dehydrogenase gene expression in two halophytic plants, Salicornia europaea and Suaeda maritima. Plant Sci. 166, 1345-1349.

Möhrlen, F., Maniura, M., Plickert, G., Frohme, M., Frank, U., 2006. Evolution of astacin-like metalloproteases in animals and their function in development. Evol. Dev. 8, 223-231.

Mortz, E., Krogh, T.N., Vorum, H., Görg, A., 2001. Improved silver staining protocols for high sensitivity protein identification using matrix-assisted laser desorption/ionization-time of flight analysis. Proteomics 1, 1359-1363.

Muñoz, I.G., Moran, J.F., Becana, M., Montoya, G., 2005. The crystal structure of an eukaryotic iron superoxide dismutase suggests intersubunit cooperation during catalysis. Protein Sci. 14, 387-394.

Neff, J.M., 1997. Ecotoxicology of arsenic in the marine environment. Environ. Toxicol. Chem. 16, 917-927.

Poulson-Ellestad, K.L., Jones, C.M., Roy, J., Viant, M.R., Fernández, F.M., Kubanek, J., Nunn, B.L., 2014. Metabolomics and proteomics reveal impacts of chemically mediated competition on marine plankton. Proc. Natl. Acad. Sci. U. S. A. 111, 9009-9014.

Ray, S., Mukherjee, S., Bhunia, N.S., Bhunia, A.S., Ray, M., 2015. Immunotoxicological Threats of Pollutants in Aquatic Invertebrates. Emerging Pollutants in the Environment-current and Further Implications. Intech, Croatia, pp. 147-165.

Sacheti, P., Patil, R., Dube, A., Bhonsle, H., Thombre, D., Marathe, S., Vidhate, R. Wagh, P., Kulkarni, M., Rapole, S., Gade, W., 2014. Proteomics of arsenic stress in the gram-positive organism Exiguobacterium sp PS NCIM 5463. Appl. Microbiol. Biotechnol. 98, 6761-6773.

Salazar, M.H., Salazar, S.M., 1987. Tributyltin Effects on Juvenile Mussel Growth. OCEANS'87. IEEE, pp. 1504-1510.

Salway, J.G., 2013. Metabolism at a Glance. John Wiley \& Sons.

Santos, E.M., Ball, J.S., Williams, T.D., Wu, H.F., Ortega, F., Van Aerle, R., Katsiadaki, I. Falciani, F., Viant, M.R., Chipman, J.K., Tyler, C.R., 2010. Identifying health impacts of exposure to copper using transcriptomics and metabolomics in a fish model. Environ. Sci. Technol. 44, 820-826.

Sarsour, E.H., Kalen, A.L., Goswami, P.C., 2014. Manganese superoxide dismutase regulates a redox cycle within the cell cycle. Antioxid. Redox Signal. 20, $1618-1627$.

Sureda, A., Tejada, S., Box, A., Deudero, S., 2013. Polycyclic aromatic hydrocarbon levels and measures of oxidative stress in the Mediterranean endemic bivalve Pinna nobilis exposed to the Don Pedro oil spill. Mar. Pollut. Bull. 71, 69-73.

Thomas, G.P., Welch, W.J., Mathews, M.B., Feramisco, J.R., 1981. Molecular and cellular effects of heat-shock and related treatments of mammalian tissueculture cells. Cold Spring Harb. Symp. 46, 985-996.

Tomanek, L., Zuzow, M.J., 2010. The proteomic response of the mussel congeners Mytilus galloprovincialis and M. trossulus to acute heat stress: implications for thermal tolerance limits and metabolic costs of thermal stress. J. Exp. Biol. 213 3559-3574.

Tsiaka, P., Tsarpali, V., Ntaikou, I., Kostopoulou, M.N., Lyberatos, G., Dailianis, S. 2013. Carbamazepine-mediated pro-oxidant effects on the unicellular marine algal species Dunaliella tertiolecta and the hemocytes of mussel Mytilus galloprovincialis. Ecotoxicology 22, 1208-1220.

Tullius, M.V., Phillips, N.J., Scheffler, N.K., Samuels, N.M., Munson, R.S., Hansen, E.J., Stevens-Riley, M., Campagnari, A.A., Gibson, B.W., 2002. The lbgAB gene cluster of Haemophilus ducreyi encodes a beta-1,4-galactosyltransferase and an alpha1,6-DD-heptosyltransferase involved in lipooligosaccharide biosynthesis. Infect. Immun. 70, 2853-2861.

Tuzen, M., 2009. Toxic and essential trace elemental contents in fish species from the Black Sea. Turk. Food Chem. Toxicol. 47, 1785-1790.

Viant, M.R., Rosenblum, E.S., Tjeerdema, R.S., 2003. NMR-based metabolomics: a powerful approach for characterizing the effects of environmental stressors on 
organism health. Environ. Sci. Technol. 37, 4982-4989.

Voorhees, J.P., Phillips, B.M., Anderson, B.S., Siegler, K. Katz, S., Jennings, L. Tjeerdema, R.S., Jensen, J., Carpio-Obeso, M.D., 2013. Hypersalinity toxicity thresholds for nine california ocean plan toxicity test protocols. Arch. Environ. Contam. Toxicol. 65, 665-670.

Waite, J.H., 1983. Evidence for a repeating 3, 4-dihydroxyphenylalanine-and hydroxyproline-containing decapeptide in the adhesive protein of the mussel, Mytilus edulis L. J. Biol. Chem. 258, 2911-2915.

Wang, M.H., Wang, Y.Y., Wang, J., Lin, L., Hong, H.S., Wang, D.Z., 2011. Proteome profiles in medaka (Oryzias melastigma) liver and brain experimentally exposed to acute inorganic mercury. Aquat. Toxicol. 103, 129-139.

Wei, L., Wang, Q., Ning, X.X., Mu, C.K., Wang, C.L., Cao, R.W., Wu, H.F., Cong, M., Li, F. Ji, C.L., Zhao, J.M., 2015a. Combined metabolome and proteome analysis of the mantle tissue from Pacific oyster Crassostrea gigas exposed to elevated $\mathrm{pCO}_{2}$. Comp. Biochem. Phys. D. 13, 16-23.
Wei, L., Wang, Q., Wu, H.F., Ji, C.L., Zhao, J.M., 2015b. Proteomic and metabolomic responses of Pacific oyster Crassostrea gigas to elevated $\mathrm{pCO}_{2}$ exposure. J. Proteom. 112, 83-94.

Worldwide, A., 2003. Documentation of the TLVs ${ }^{\circledR}$ and BEIs ${ }^{\circledR}$ with Other Worldwide Occupational Exposure Values-CD-ROM-2003. Cincinnati, OH.

Wu, H.F., Southam, A.D., Hines, A., Viant, M.R., 2008. High-throughput tissue extraction protocol for NMR- and MS-based metabolomics. Anal. Biochem. 372, 204-212.

Wu, H.F., Wang, W.X., 2010. NMR-based metabolomic studies on the toxicological effects of cadmium and copper on green mussels Perna viridis. Aquat. Toxicol. $100,339-345$

Wu, H.F., Zhang, X.Y., Wang, Q., Li, L.Z., Ji, C.L., Liu, X.L., Zhao, J.M., Yin, X.L., 2013. A metabolomic investigation on arsenic-induced toxicological effects in the clam Ruditapes philippinarum under different salinities. Ecotoxicol. Environ. Saf. $90,1-6$ 